\title{
Comparison of Three Evolutionary Algorithms: PSOA, ACOA And BCOA on Recognition Arabic Characters Problem
}

\author{
Prof. Majida Ali Abed , Assist Lecture Ahmed Naser Ismael \\ College of Computers Sciences \& Mathematics, Tikrit University, Tikrit, Iraq \\ Majida.alasady@gmail.com, ahmadnassir84@gmail.com
}

\begin{abstract}
Intelligence techniques such as Particle swarm optimization, Genetic algorithm, Ant colony optimization , Bee Colony Optimization can apply on the system as classification method for better result This paper we survey three techniques Ant Colony Optimization Algorithm (ACOA), Particle Swarm Optimization Algorithm (PSOA), and Bee Colony Optimization Algorithm (BCOA),their algorithm and reason to use. In recent years, the area of Evolutionary Computation has come into these three. Three of the popular developed approaches are Particle Swarm Optimization Algorithm (PSOA), Ant Colony Optimization Algorithm (ACOA) and Bee Colony Optimization Algorithm (BCOA), are used in optimization problems. Since the three approaches are supposed to find a solution to a given objective function but employ different strategies and computational effort, it is appropriate to compare their implementation. The problem area chosen is that recognition of Final forms of Arabic handwritten characters.
\end{abstract}

KEYWORDS: particle swarm optimization Algorithm (PSOA), Ant Colony Optimization Algorithm (ACOA), Bee Colony Optimization Algorithm (BCOA), recognition system.

\section{INTRODUCTION}

There are mainly three phases of a character recognition system: Preprocessing, Segmentation, Recognition. The preprocessing technique removes noise, irrelevant data and unwanted data. In Recognition system has to recognize the object such as character, number, symbol .....etc. , in defined way[1,2]. The swarm intelligent techniques are considered the most modern artificial intelligence techniques, which contains many approaches that are used to solve optimization problems with high presentation and effectiveness and appropriate behavior to solve various optimization problems such as character recognition and make a comparison among them in term of behavior and presentation. Many approaches is presented that used different swarm intelligence techniques such as Ant Colony Optimization (ACO), Bees Algorithm (BA), and Particle Swarm Optimization (PSO), the swarm intelligence techniques success in solving practical, important, and applicable problems with high presentation, effectiveness, and particular behavior[3,4].

There are three main processes in all evolutionary algorithms:

- initialization process

- evaluation process for fitness value

- generation process of a new population 
In the initialization process, the initial population of individuals (directly or indirectly) is randomly generated according to some solution representation. In the evaluation, process evaluated for fitness value can be used to calculate the average population fitness that by fitness function for the purpose $[5,6]$.

Of selection.in the third process is the generation of a new population, the three processes are shown in Figure (1), after initialization, the population is evaluated and stopping criteria are checked. If none of the stopping criteria is met, a new population is generated again and the process is repeated until one or more of the stopping criteria are met [7]. The processes for initialization and generation of new population may produce infeasible solutions. It is very important to choose a solution representation that is more likely to produce feasible solutions. This is a common design consideration for all evolutionary algorithms. In addition to the solution representation, two common parameters that must be determined initially are $[8,9]$.

- population size

- Maximum number of iteration.

The choices of values of these two parameters have officer effect on the solution quality and solution time, these values are usually determined in practice [10].

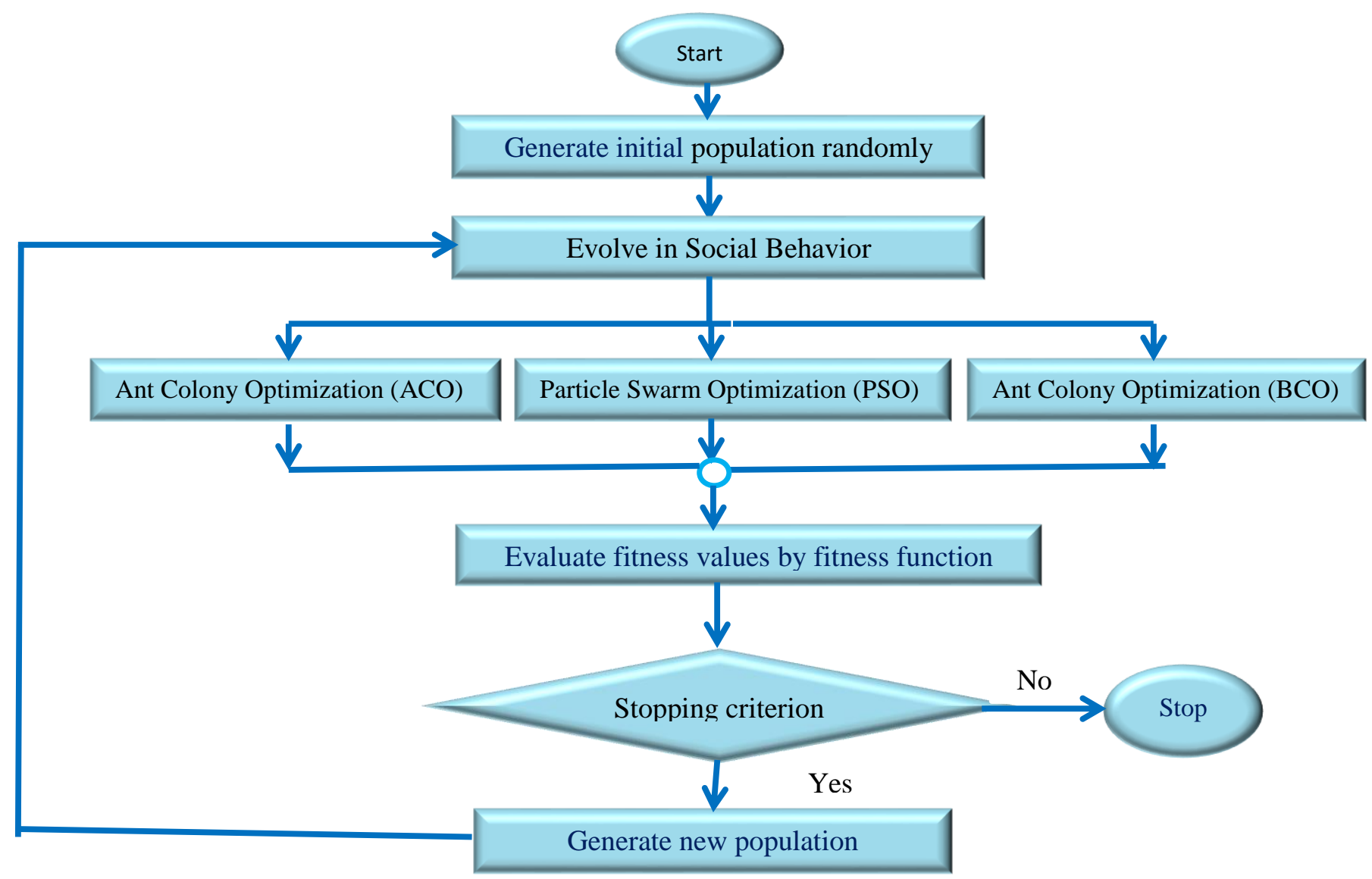

Fig .I: General three main processes of evolutionary algorithm ACOA, PSOA and BCOA

In this paper use comparison between Particle Swarm Optimization Algorithm (PSOA), Ant Colony Optimization Algorithm (ACOA) and Bee Colony Optimization Algorithm (BCOA), for recognition 
handwritten Arabic characters with final forms, we reach to scientific discussion and conclusions that differentiate among the presented approaches to prove that the three evolutionary algorithms succeed in solving convenient, important, and appropriate problems with high presentation, effectiveness, and particular behavior. Arabic characters might be confusing; because Arabic has many characters have different forms depending on whether they occur at the beginning, middle, or at the end of the word.

\section{THREE EVOLUTIONARY ALGORITHMS EAs}

In general, EAs share a common approach for their application to a given problem. The problem first requires some representation to suit each method. Then, the evolutionary search algorithm is applied iteratively to arrive at a near-optimum solution. Evolutionary algorithms have been lengthily developed and used as search and optimization tools in various problem domains, such as (Ant Colony Optimization, Particle Swarm Optimization Algorithm, Bee Colony Optimization Algorithm ...etc. .Their comprehensive applicability, comfort of use, and global perspective may be considered as the primary reason for their success This paper deals with the implementation of the recognition handwritten Arabic characters by using three different Evolutionary Algorithm EAs that are Ant Colony Optimization Algorithm, Particle Swarm Optimization Algorithm and Bee Colony Optimization Algorithm then we compare the results of recognition and find the best optimization algorithm with high percentage of accuracy[11]. Many researchers were proposed to overcome disadvantages of the classical

Optimization procedures. These new techniques stimulated heuristic optimization algorithms are efficient and stretchy. They can be modified and/or modified to suit specific problem necessities Figure (2) explain modern. heuristic optimization strategies Research on these techniques is still continuing all around the globe.

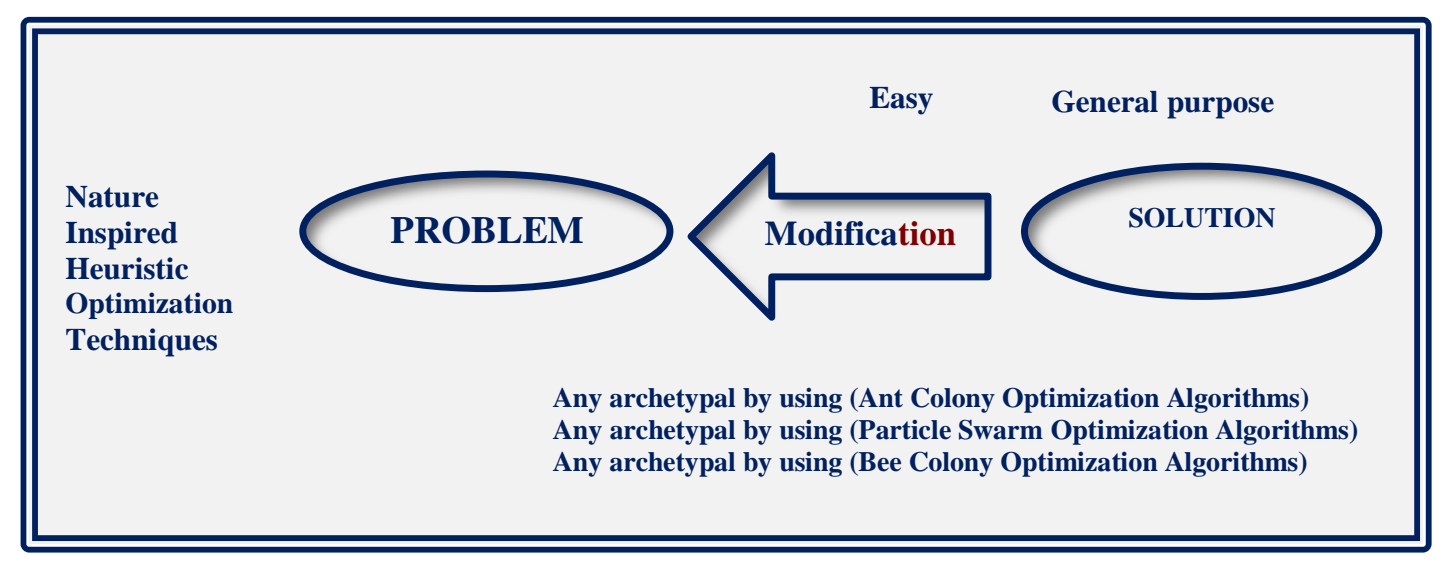

Fig .II: Modern heuristic optimization strategies

\subsection{Ant Colony Optimization Algorithm (ACOA)}

Ant colony Optimization Algorithm is a part of swarm intelligence approach that has been successfully used in optimization technique. It was proposed by Marco Dorigo in the year 1992[12].Can be used in any optimization problem and has been successfully applied in the selection of optimal minimal of 
feature [13]. ACO based on the foraging behavior of ant and shall be deposited same amount of pheromone on their paths in order to work an enabling path that should be followed by other ant of the colony so shorter path will receive more pheromone per time unit. In addition, the amount of pheromone on each path decreases as time passes because of vaporization. Therefore, longer paths lose their pheromone Density and become less favorable over time. Ant algorithms are stimulated by real ant colony, Probability of ant following assured path is a function, Pheromone concentration, Visibility, Evaporation, The aim of ant colony optimization algorithm is to find an optimal path from source to target and it used for solving many problems such as Travelling Salesman Problem (TSP), Quadratic Assignment Problem (QAP), Vehicle Routing, Stock Cutting and recognition characters the ACO consists of three major concepts: construction ant solution, applying local search, updating pheromones [14] Figure (3) explain the flow chart of ACO.

\subsection{Particle Swarm Optimization Algorithm (PSOA)}

The Particle Swarm Optimization algorithm (PSOA) was originally designed by Kennedy and Eberhart in 1995. PSOA is a population based searching method which imitates the social behavior of birds or fish schooling. The population is called a "swarm" and the individuals are called "particles". Each particle moves in the swarm with a velocity that is adjusted according to its own flying experience and retains the best position. It ever encountered in memory. The best local and global positions ever encountered by all particles of the swarm are also communicated to all particles. Advantages of PSOA have no mutation calculation and overlapping. PSOA compared with the other Evolutionary Algorithms, it occupies the better optimization ability and it can be completed easily. Figures (4) explain the flow chart of PSOA [15].

\subsection{Bee Colony Optimization Algorithm (BCOA)}

The Bees Colony Optimization Algorithm is a natural phenomenon of bee colony, population-based search algorithm inspired by the natural foraging behavior of honey bees to find the optimal solution. The idea behind the BCO is to create the multi agent system (colony of artificial bees) capable to successfully solve difficult combinatorial Optimization problems; the algorithm performs a kind of neighborhood random search [16]. There are three types of bees: Queen Bee there is one queen bee in the bee colony. She is responsible to lay eggs which are used to build new colonies, Male Drone Bees there are many male drone bees in the ant colony; these are responsible for mating with the queen bee and Worker Bees There are thousands worker bees in the ant colony, these bees perform all the preservation and management jobs in the colony and the scout behavior and forager behavior respectively are collectively responsible for the working of the honey bee colonies. There are two types of worker bees, scout bees and Forager bees. In execution of the Bee Colony Optimization algorithm following three paths will be formed as Path Construction (PSB), Path Restructuring (PFB) and Path Selection (PS) . Figures (5) explain the flow chart of BCOA [17]. 

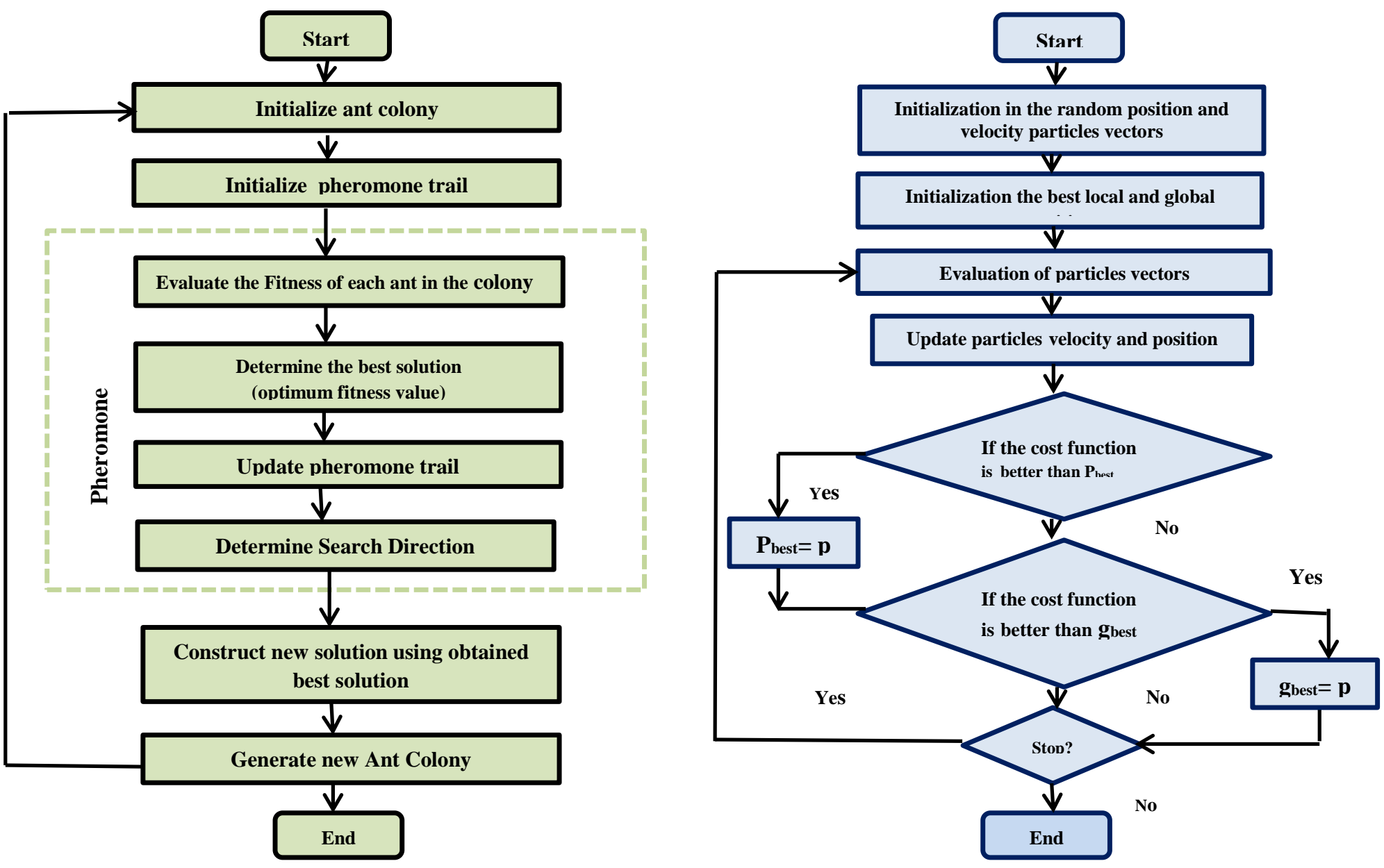

Fig III: Flowchart of Ant Colony Optimization Algorithm (ACOA)

Fig. IV: Flowchart of Particle Swarm Optimization Algorithm (PSOA)

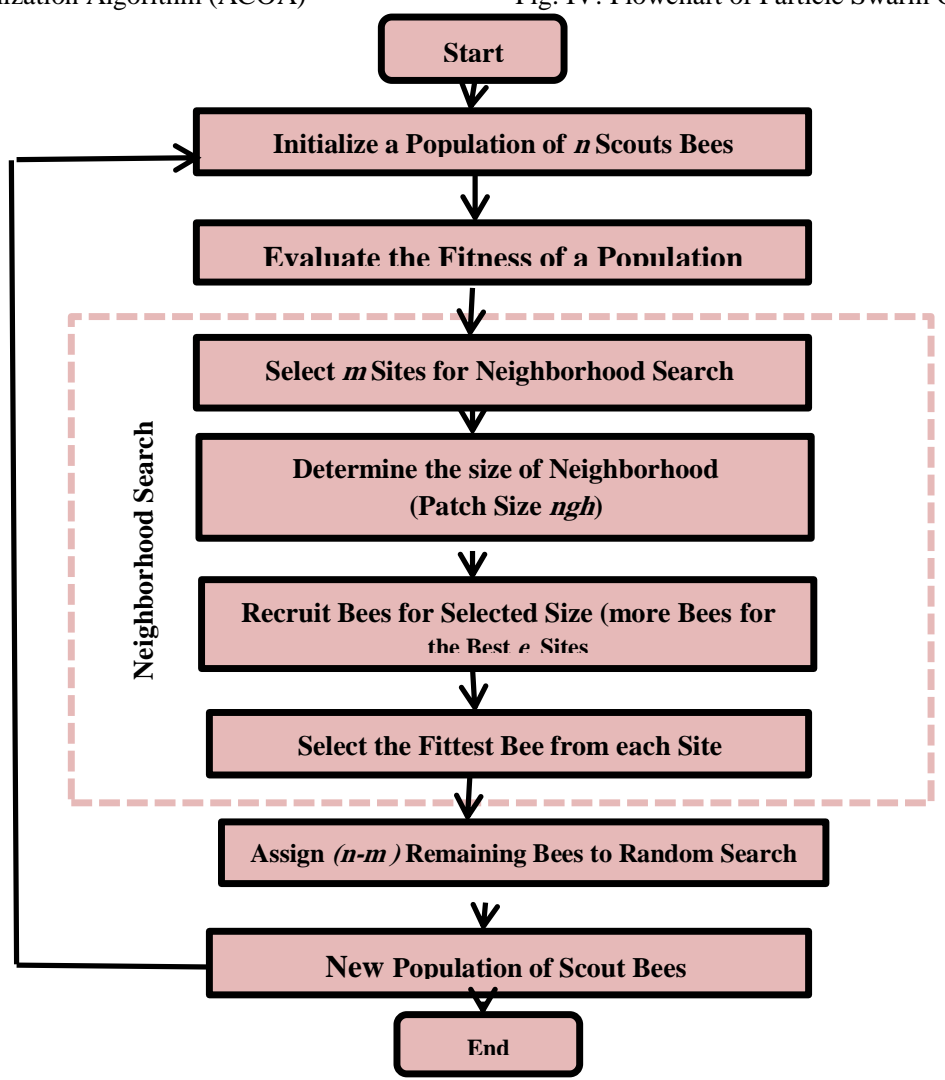

Fig V: Flowchart of Bee Colony Optimization Algorithm (BCOA) 


\subsection{Comparison between (PSOA), (ACOA) and (BCOA)}

Evolutionary Algorithms (EAs) such as Particle Swarm Optimization (PSO), Ant Colony Optimization (ACO), artificial fish swarm algorithm (AFSA), Bee Colony Optimization (BCO), Artificial bee colony (ABC), Firefly algorithm (FA), Bat algorithm (BA) and so on, have successfully been applied to a wide variety of optimization problems, for example: image processing, pattern recognition, scheduling, engineering design, etc. ,It is important to point out that all algorithms try to produce a good optimality solution without conceding accuracy in the data classification. Most of evolutionary Algorithms have the following steps as show in figure (6).

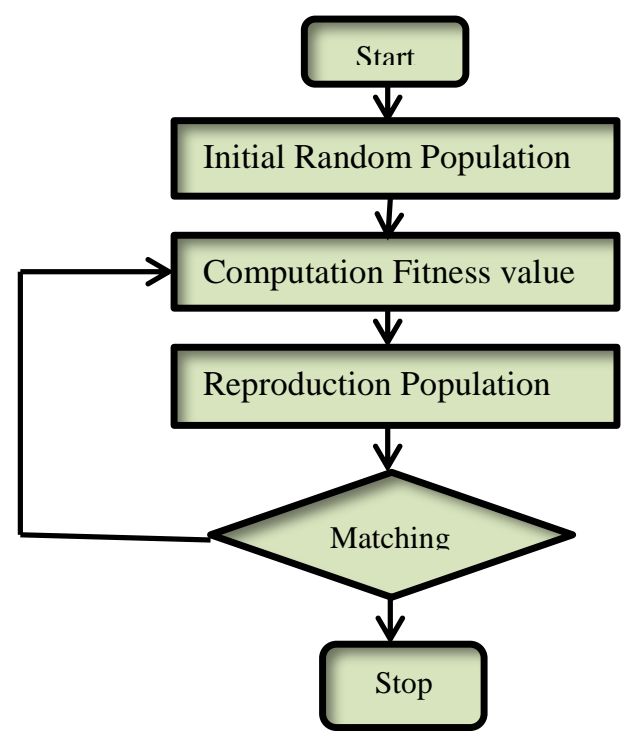

Fig. VI: General steps of evolutionary Algorithms (EAs)

From the steps of figure above, we can saw that the three algorithms PSO, ACO and BCO start with randomly generated population, the three algorithms have fitness values to evaluate the population., update the population and search for the optimum with random techniques and do not guarantee that their steps will success. The three algorithms have some advantages, some disadvantages and their application. Table (1) show the advantages and disadvantages of PSOA, ACOA and BCOA. 
Table (1) Advantages and disadvantages of PSOA, ACOA and BCOA.

\begin{tabular}{|c|c|c|c|}
\hline Algorithm & Description & Advantages & Disadvantages \\
\hline PSOA & Behavior of flocks of birds. & $\begin{array}{l}\text { 1. Based on the intelligence. It can be applied into } \\
\text { Both scientific research and engineering use. } \\
\text { 2. Have no overlapping and mutation calculation and } \\
\text { Calculation is very simple. }\end{array}$ & $\begin{array}{l}\text { 1.optimism, which causes the less } \\
\text { exact at the regulation of its speed } \\
\text { and the direction } \\
\text { 2.cannot work out the problems of } \\
\text { Scattering and optimization. } \\
\text { 3. The method cannot work out the } \\
\text { problems of non-coordinate } \\
\text { system, such as the solution to the } \\
\text { energy field and the moving rules } \\
\text { of the particles in the energy field. }\end{array}$ \\
\hline $\mathrm{ACOA}$ & $\begin{array}{l}\text { Behavior of real ant colonies } \\
\text { solution construction and } \\
\text { pheromone update are two key } \\
\text { issues for an ant colony } \\
\text { algorithm }\end{array}$ & $\begin{array}{l}\text { 1.Inherent parallelism } \\
\text { 2. Positive Feedback accounts for rapid discovery } \\
\text { Of good solutions } \\
\text { 3. Efficient for Traveling Salesman Problem and } \\
\text { similar problems } \\
\text { 4. Can be used in dynamic applications (adapts to } \\
\text { changes such as new distances) } \\
\text { 5.Distributed computation avoids premature } \\
\text { Convergence. }\end{array}$ & $\begin{array}{l}\text { 1. Theoretical analysis is difficult } \\
\text { 2.Sequences of random decisions } \\
\text { (not independent) } \\
\text { 3. Probability distribution changes by } \\
\text { iteration } \\
\text { 4. Research is experimental rather than } \\
\text { theoretical } \\
\text { 5. Time to convergence uncertain } \\
\text { 6. defects of searching local } \\
\text { optimization and slow convergence } \\
\text { speed }\end{array}$ \\
\hline $\mathrm{BCOA}$ & Behavior of real bee colonies & $\begin{array}{l}\text { 1. Simplicity, flexibility and robustness } \\
\text { 2. Use of fewer control parameters compared too } \\
\text { Many other search techniques]. } \\
\text { 3. Ease of hybridization with other optimization } \\
\text { Algorithms. } \\
\text { 4. Ability to handle the objective cost with } \\
\text { Stochastic nature. } \\
\text { 5. Ease of implementation with basic } \\
\text { Mathematical and logical operations. }\end{array}$ & $\begin{array}{l}\text { Convergence performance for local } \\
\text { minimum is slow. }\end{array}$ \\
\hline
\end{tabular}

\section{KNOWLEDGE BASE AND EXPERIMENTAL ANALYSIS}

\subsection{Knowledge Base}

The knowledge base used the scanned input final Handwritten Arabic Characters, in our experiments, after normalization process which is performed so that all Characters could become in equal dimensions of matrix. In this paper database consists 28 final characters from I to each character has different ten forms written by hand Arrange in separate file for each character. The Training database consists of 667 samples for characters (ي-إ), 28 saved as database, 639 characters with different forms input samples. We use Matlab to extract the handwritten character for each file. The six different forms of final Arabic handwritten characters are shown in figure (7). 


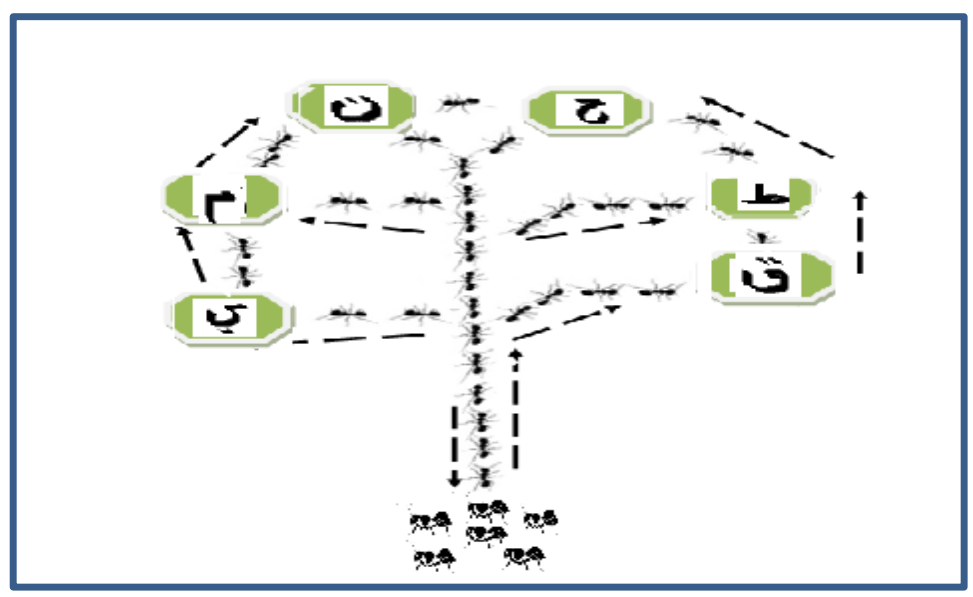

Fig .VIII: Ants path for searching final Arabic handwritten character

\section{RESULT AND DISCUSSION}

in our proposed model we have input final forms of Arabic handwritten characters, and explain how the proposed model make matching between the inputs characters and the original characters in database to obtain the best ratio matching by using Ant Colony Optimization Algorithm(ACOA),Particles Swarm Optimization Algorithm (PSOA) and Bee Colony Optimization Algorithm (BCOA), the input and original characters a were analyzed by matlab program version 7.0 to get the resolution for every character as shown in the table(2).

Table (2): Best ratio matching of all final Arabic characters in database with input Arabic handwritten Characters with Clarity inventory

\begin{tabular}{|c|c|c|c|c|c|c|c|c|c|c|c|c|c|c|c|}
\hline 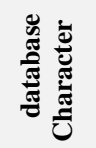 & 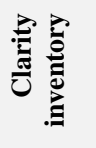 & 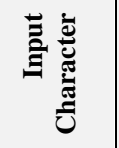 & 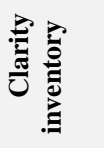 & 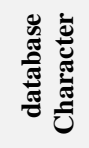 & 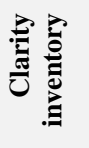 & 童苔 & 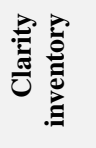 & 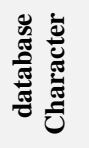 & 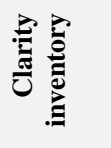 & 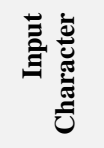 & 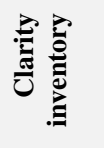 & 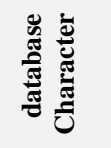 & 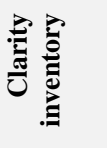 & 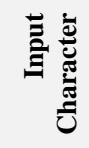 & 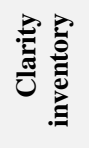 \\
\hline$L$ & 93.776 & L & 83.622 & - & 87.778 & 工 & 78.663 & هن & 91.547 & ن & 79.324 & $\stackrel{5 \perp}{\longleftarrow}$ & 88.876 & 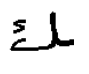 & 80.322 \\
\hline C. & 89.887 & r. & 78.221 & 2 & 88.678 & $\perp$ & 76.665 & & 86.764 & 10 & 75.344 & $\mathcal{L}$ & 90.674 & 5 & 80.345 \\
\hline$\ddot{x}$ & 86.443 & 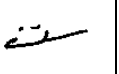 & 76.265 & $\mu$ & 84.413 & $\Gamma$ & 73.332 & b & 90.985 & 18 & 80.235 & co- & 80.664 & $\sigma$ & 72.231 \\
\hline ستن & 90.987 & $\therefore$ & 79.334 & 5 & 89.559 & & 78.998 & $z$ & 88.776 & $z$ & 77.151 & $v$ & 85.664 & 5 & 74.224 \\
\hline$\approx$ & 88.789 & $\mathcal{c}$ & 80.554 & س س & 92.776 & $\sqrt{-2}$ & 80.445 & & 89.778 & $z$ & 79.552 & $\alpha$ & 89.663 & $a$ & 79.432 \\
\hline 2 & 85.663 & $\leftarrow$ & 77.554 & & 88.987 & س & 77.664 & & 88.554 & w & 76.112 & 5 & 91.587 & 9 & 82.176 \\
\hline 2 & 88.954 & $\dot{z}$ & 76.554 & & 91.985 & ve & 80.553 & 9 & $\begin{array}{l}91.598 \\
\end{array}$ & 5 & 82.332 & $\ldots$ & $\begin{array}{l}88.887 \\
\end{array}$ & $=s$ & 76.412 \\
\hline
\end{tabular}


The input characters will be comparing final Arabic handwritten characters with the original character in the database that include six forms for each character, where every input character will matching with six forms for same character, to know the input characters with the original six characters may be different matching or

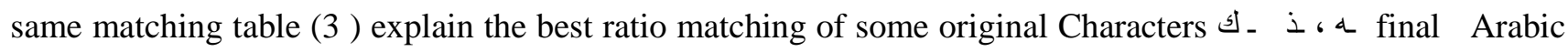
characters in the database with Input character handwritten by using ACOA,PSOA and BCOA, and figure (9)

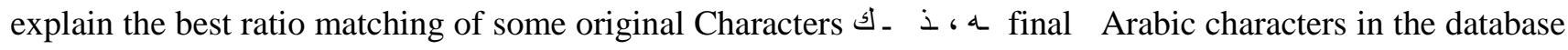
with Input character handwritten by using BCOA ,table (4) explain the best ratio matching of all final Arabic Characters ratio matching in database with input Arabic handwritten character by using ACOA, PSOA and BCOA, table(5) and figure(10) explain the recognition rate by using ACOA, PSOA and BCOA which are $90.06 \% 87.32 \% 91.98 \%$. Experimental results show that the BCOA is convergence and more accurate in solution.

Table (3): Best ratio matching of the Characters 3 ، i ، a in database with input characters by using ACOA, PSOA and BCOA

\begin{tabular}{|c|c|c|c|c|c|c|c|}
\hline $\begin{array}{l}\text { Six forms in } \\
\text { the database for } \\
\text { each character }\end{array}$ & $\begin{array}{c}\text { Original } \\
\text { Characters } \\
\text { handwritten } \\
\text { in database }\end{array}$ & $\begin{array}{c}\text { Clarity } \\
\text { handwritten } \\
\text { character inventory } \\
\text { (Resolution) }\end{array}$ & $\begin{array}{c}\text { Input } \\
\text { handwritten } \\
\text { Characters }\end{array}$ & $\begin{array}{c}\text { Clarity } \\
\text { handwritten } \\
\text { character input } \\
\text { (Resolution) }\end{array}$ & $\begin{array}{c}\text { Best Matching to } \\
\text { handwritten characters } \\
\text { by ACOA }\end{array}$ & $\begin{array}{c}\text { Best Matching to } \\
\text { handwritten characters } \\
\text { by PSOA }\end{array}$ & $\begin{array}{c}\text { Best Matching to } \\
\text { handwritten characters } \\
\text { by BCOA }\end{array}$ \\
\hline$\frac{a}{a-a}$ & $\alpha$ & 89.663 & $a$ & 79.432 & $90.2 \%$ & $91.4 \%$ & $92.6 \%$ \\
\hline 3 & $\dot{2}$ & 88.678 & $j$ & 76.665 & $90.5 \%$ & $89.6 \%$ & $91.5 \%$ \\
\hline 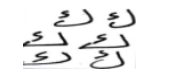 & 2 & 88.876 & $\stackrel{s}{c}$ & 80.322 & $92.5 \%$ & $90.5 \%$ & $92.8 \%$ \\
\hline
\end{tabular}

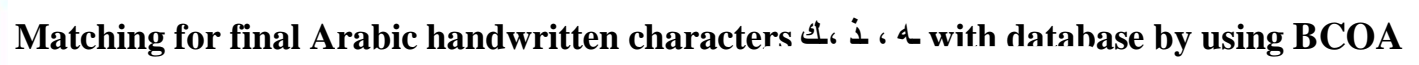

\begin{tabular}{|l|c|c|c|}
\hline & \multicolumn{3}{l|}{} \\
\cline { 2 - 4 } & \multicolumn{3}{l|}{$\begin{array}{c}\text { Clarity handwritten character input (Resolution) } \\
\text { Clarity handwritten character inventory... }\end{array}$} \\
\hline
\end{tabular}

Fig. IX: Matching for final Arabic Character 14 ، $i$ ، @ with database by using BCOA 
Table (4): Best ratio matching of final Arabic Characters in database with input final Arabic handwritten character by Using ACOA, PSOA\& BCOA

\begin{tabular}{|c|c|c|c|c|c|c|c|c|c|c|c|c|c|c|c|c|c|c|c|c|c|c|c|c|c|c|c|c|c|}
\hline & & - & J. & :] & ג] & N. & $\mathrm{N}$ & N & $\tau$ & . & & ? & 3 & $\because 3$ & f & 3 & $\rightarrow$ & $\rightarrow$ & $\omega$ & $\omega$ & $\cdot g$ & 9 & चा & J & 2 & כ. & . & 9 & $y$ \\
\hline 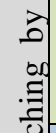 & $\begin{array}{l}\overleftarrow{\delta} \\
0 \\
0\end{array}$ & $\stackrel{\circ}{\circ}$ & $\frac{\circ}{\infty}$ & $\frac{\circ}{8}$ & $\begin{array}{l}\stackrel{\circ}{ } \\
\vec{i}\end{array}$ & $\begin{array}{l}\stackrel{\circ}{ } \\
+ \\
\infty \\
\infty\end{array}$ & $\stackrel{\stackrel{\circ}{-}}{\overrightarrow{\bar{a}}}$ & $\frac{\stackrel{0}{\circ}}{\infty}$ & 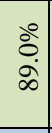 & $\begin{array}{l}\vdots \\
\vdots \\
\vdots\end{array}$ & $\begin{array}{l}\stackrel{0}{0} \\
m \\
\infty \\
\infty\end{array}$ & $\begin{array}{l}\stackrel{8}{0} \\
\dddot{m} \\
\infty\end{array}$ & $\begin{array}{l}\text { bे } \\
\text { t. } \\
\text { के }\end{array}$ & 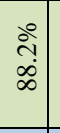 & $\begin{array}{l}\stackrel{\circ}{\circ} \\
+ \\
\infty \\
\infty\end{array}$ & $\begin{array}{l}\stackrel{0}{2} \\
\stackrel{8}{8}\end{array}$ & $\begin{array}{l}\dot{0} \\
\dot{\alpha} \\
\infty\end{array}$ & 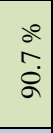 & $\begin{array}{l}\stackrel{0}{0} \\
0 \\
\stackrel{\infty}{\infty}\end{array}$ & 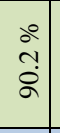 & $\begin{array}{c}0 \\
0 \\
\dot{\infty} \\
\infty \\
\infty\end{array}$ & $\mid \begin{array}{c}\mid \\
\stackrel{2}{0} \\
\vdots \\
\end{array}$ & $\begin{array}{l}0 \\
i \\
i \\
\sigma\end{array} \mid$ & 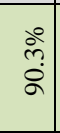 & $\begin{array}{l}\stackrel{8}{ } \\
\dot{+} \\
\text { a }\end{array}$ & \begin{tabular}{l}
$\stackrel{0}{0}$ \\
\multirow{a}{*}{} \\
$\dot{a}$
\end{tabular} & 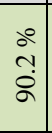 & 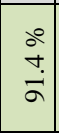 & $\begin{array}{l}0 \\
0 \\
+\infty \\
\infty\end{array}$ \\
\hline$\sum_{-}^{\frac{\pi}{2}}$ & $\begin{array}{l}\mathbb{b} \\
\tilde{n} \\
\alpha\end{array}$ & 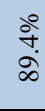 & $\stackrel{2}{\stackrel{2}{\infty}}$ & 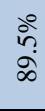 & $\begin{array}{l}\text { bे } \\
\infty \\
\infty \\
\infty\end{array}$ & $\begin{array}{l}\overbrace{0}^{\circ} \\
\stackrel{-}{\sigma}\end{array}$ & $\begin{array}{l}\infty \\
\infty \\
\dot{a}\end{array}$ & $\begin{array}{l}\stackrel{\circ}{\circ} \\
\stackrel{\infty}{\infty}\end{array}$ & 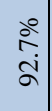 & : & $\frac{\stackrel{0}{m}}{\sigma}$ & $\frac{\substack{\stackrel{0}{\infty} \\
\infty \\
\infty}}{\infty}$ & $\begin{array}{l}\stackrel{0}{\circ} \\
\infty \\
\infty\end{array}$ & ڤ̊ & 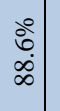 & 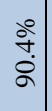 & $\begin{array}{l}\vdots 0 \\
\vdots \\
\vdots \\
\infty\end{array}$ & 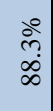 & $\begin{array}{c}0 \\
\vdots \\
\vdots \\
\vdots \\
\vdots\end{array}$ & 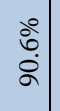 & $\begin{array}{l}\stackrel{\circ}{0} \\
\dot{0}\end{array}$ & $\begin{array}{l}\stackrel{\circ}{\tilde{J}} \\
\text { ă }\end{array}$ & $\begin{array}{c}30 \\
n \\
2 \\
2\end{array}$ & 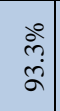 & $\frac{\stackrel{2}{2}}{\dot{a}}$ & $\begin{array}{c}3 \\
0 \\
0 \\
\tilde{n}\end{array}$ & 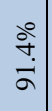 & $\begin{array}{c}0 \\
0 \\
\vdots \\
\vdots \\
\delta\end{array}$ & $\begin{array}{c}\stackrel{0}{0} \\
\grave{a} \\
\infty\end{array}$ \\
\hline$\stackrel{D}{0}$ & 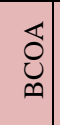 & 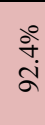 & $\stackrel{\circ}{\stackrel{2}{a}}$ & 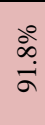 & $\stackrel{\text { }}{\stackrel{2}{\sigma}}$ & $\begin{array}{l}\stackrel{8}{0} \\
\text { ळू. }\end{array}$ & 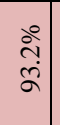 & 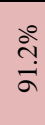 & 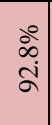 & 光 & 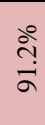 & 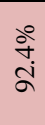 & $\begin{array}{l}\overbrace{}^{\circ} \\
\stackrel{-}{\circ}\end{array}$ & $\begin{array}{l}\underbrace{\circ}_{0} \\
\dot{\alpha}\end{array}$ & 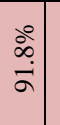 & 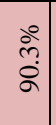 & $\begin{array}{l}\frac{0}{\circ} \\
\stackrel{+}{+}\end{array}$ & 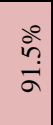 & $\begin{array}{l}\infty \\
\vdots \\
\dot{0} \\
\vdots\end{array}$ & 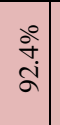 & 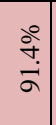 & $\begin{array}{l}\infty \\
\infty \\
\dot{a}\end{array}$ & $\begin{array}{l}\infty \\
\infty \\
\infty \\
j\end{array}$ & 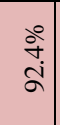 & $\begin{array}{l}\infty \\
\infty \\
\text { à }\end{array}$ & 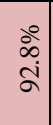 & 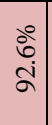 & $\begin{array}{l}\delta \\
\infty \\
i \\
i\end{array}$ & $\begin{array}{l}\stackrel{0}{0} \\
\text { aे }\end{array}$ \\
\hline
\end{tabular}

Table (5): the recognition rate of final Arabic Characters by using ACOA, PSOA and BCOA

\begin{tabular}{|c|c|}
\hline Algorithm & Recognition rate \% \\
\hline ACOA & $90.06 \%$ \\
\hline PSOA & $87.32 \%$ \\
\hline BCOA & $91.98 \%$ \\
\hline
\end{tabular}

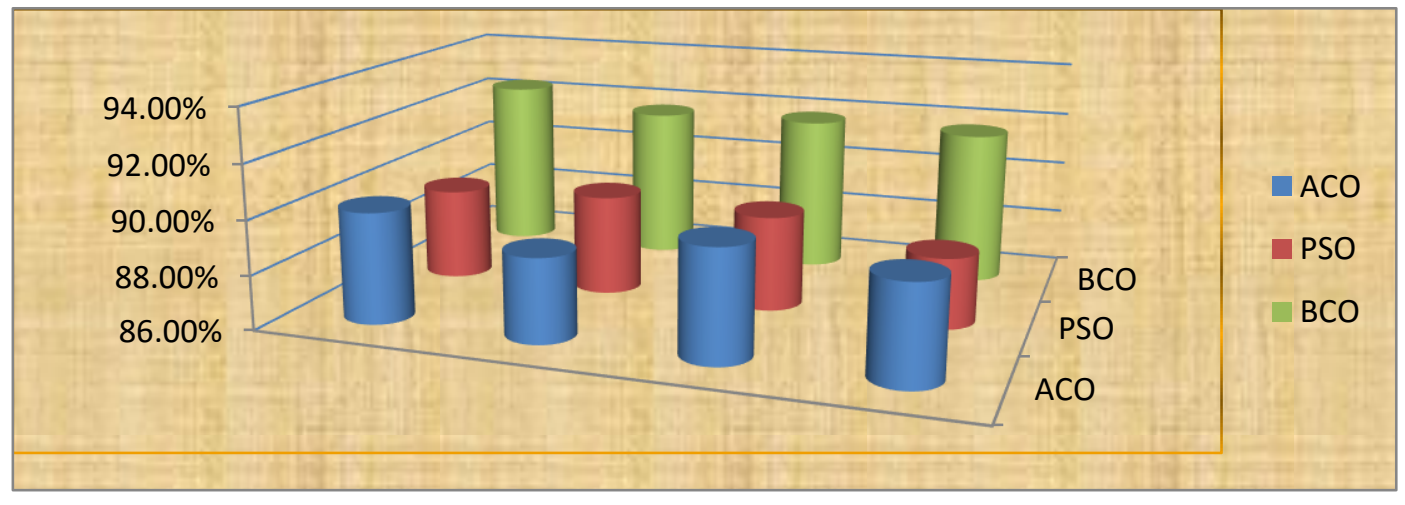

\section{V.CONCLUSIONS}

Fig .X: the recognition rate by using ACOA, PSOA and BCOA

In our paper, evolutionary techniques such as ACOA, PSOA and BCOA were proven in a lifelike scenario and successfully applied for the recognition final handwritten arabic characters problem. In our present paper, a model of handwritten Arabic characters recognition using the concept of particles swarm optimization algorithm, Ant colony optimization algorithm and Bee colony optimization algorithm, have been discussed. It is noted that the BCOA in general generates an optimized matching between the input final Arabic handwritten characters and final Arabic Characters in database which improves the final recognition rate. The model has been tested with a lot of final Arabic handwritten characters, high recognition rate has recorded .We obtain Best Matching to handwritten characters by using BCOA equal to $91.98 \%$. A comparsion between these algorithms can also be made to overwhelmed the time intricacy and local optimization problems which can provide better investigation of search process and applied for future work. 


\section{REFERENCES}

[1] Rahul Kala, Harsh Vazirani, Anupam Shukla and Ritu Tiwari,( 2010), "Offline Handwriting Recognition using Genetic Algorithm”, IJCSI International Journal of Computer Science Issues, Vol. 7, Issue 2, No 1.

[2] Chidambaran, C. and Lopes, H. S., (2010), "An Improved Artificial Bee Colony Algorithm for the Object Recognition Problem in Complex Digital Images Using Template Matching", International Journal of Natural Computing Research, Vol1, No.2.

[3] E. Elbeltagi, T. Hegazy, and D. Grierson,( 2005), "Comparison among Five Evolutionary-Based Optimization Algorithms",Advanced Engineering Informatics, Vol. 19, No. 1.

[4] T Hashni et al,( 2012 ), "Relative Study of CGS with ACO and BCO Swarm Intelligence Techniques”,.. IJCTA .Computer Technology \& Applications, Vol. 3 No.5 .

[5] Elbeltagi, E., Hegazy, T., \& Grierson, D. (2005), " Comparison Among Five Evolutionary-based Optimization Algorithms", Advanced Engineering Infrastructure, Vol.19 No.1.

[6] Yu, X. and Gen, M., (2010), "Introduction to Evolutionary Algorithms", Springer, London, UK.

[7]. E.Corchado,( 2006)," PSO and ACO in Optimization Problems", Publishers : Springer - Verlag,.

[8] Yang Xiao, Xuemei Song and Zheng YAO. (2009), "improved Ant colony optimization with particle swarm optimization operator solving continuous optimization problems", IEEE.

[9] Khan. K and Sahai. A. (2012)," A comparison of BA, GA, PSO, BP and LM for training feed forward neural networks in e-learning context", International Journal of Intelligent Systems and Applications (IJISA).Vol. 4, No.7. [10] T Hashni et al,( 2012), "Relative Study of CGS with ACO and BCO Swarm Intelligence Techniques",Int Computer Technology \& Applications, IJCTA,Vol. 3 No.5 .

[11] Baijal A, Chauhan VS, Jayabarathi T (2011)," Application of PSO, artificial bee colony and bacterial foraging optimization algorithms to economic load dispatch", An analysis. Int. J. Computer Science, Vol.8, No.4.

[12] M. Dorigo and L. M. Gambardella, (1997),"The colony system: A cooperative learning approach to the traveling salesman problem", IEEE Transactions on Evolutionary Computation, Vol.1, No.1.

[13] M. Dorigo and G. Di Caro, (1999), "The Ant Colony Optimization meta-heuristic in New Ideas in ptimization", [14]M. Dorigo and T. Stützle, (2002)," The ant colony optimization meta-heuristic: Algorithms, applications and advances", In F. Glover and G. Kochenberger editors, Handbook of Meta-heuristics, Vol. 57 of International Series in Operations Research \& Management Science.

[15] Frans van den Bergh.,( 2001)," An Analysis of Particle Swarm Optimizers", PhD thesis, University of Pretoria, [16] R. Sagayam1, Mrs. K. Akilandeswari,( 2012) "Comparison of Ant Colony and Bee Colony Optimization for Spam Host Detection", International Journal of Engineering Research and Development ISSN: 2278-067X, 800X, Vol.4,No.8.

[17] Hemant Nagpure\#, Rohit Raja, (2012),"The Applications Survey on Bee Colony Optimization",(IJCSIT) International Journal of Computer Science and Information Technologies, Vol. 3,No.5.

[18] Dorigo M. (2010),"The ant system: optimization by a colony of cooperating agents". IEEE Trans Syst Man Cybern Part Byword Academy of Science, Engineering and Technology Vol.38 . 